\title{
Revendo a cidade pelos olhos das crianças: "O passeio", de João Carrascoza
}

\author{
Pascoal Farinaccio \\ Universidade Federal Fluminense
}

\begin{abstract}
Resumo
Este artigo propõe a análise crítica do conto "O passeio", que integra o livro Aquela água toda (2018), de João Carrascoza, buscando destacar a relação que as personagens infantis estabelecem com o espaço urbano - uma relação decisivamente marcada pela capacidade de rever a cidade com disposição afetiva e imaginação. Para tanto, busca-se apoio teórico nas reflexões do filósofo James Hillman em torno da importância psicológica dos lugares e da necessidade da criação permanente de novas percepções para que se mantenha viva a alma da cidade. Por fim, faz-se um breve contraponto com o texto "São Paulo", de Marcílio Castro, procurando vincular a lição perceptiva das crianças à observação adulta.
\end{abstract}

Palavras-chave: João Anzanello Carrascoza; conto brasileiro contemporâneo; cidade e alma.

\begin{abstract}
This article proposes a critical analysis of the short story "O passeio", which integrates the book Aquela água toda (2018) by João Carrascoza, aiming to highlight the relationship that children's characters establish with urban space - a relationship decisively marked by the ability to review the city with affective disposition and imagination. For this, we seek theoretical support in the reflections of philosopher James Hillman on the psychological importance of places and the need for permanent creation of new perceptions to keep alive the soul of the city. Finally, there is a brief counterpoint to the text "São Paulo", by Marcílio Castro, trying to link the children's perceptive lesson to adult observation.
\end{abstract}

Keywords: João Anzanello Carrascoza; contemporary Brazilian tale; city and soul.

Recebido em: 22/03/19

Aprovado em: 14/07/19

A cidade, a maior dentre as obras de arte humanas, pertence ao reino da imaginação.

James Hillman

O filósofo e psicólogo junguiano James Hillman dedicou boa parte de sua reflexão crítica, consubstanciada numa vasta produção bibliográfica, à importância psicológica de lugares e objetos na vida cotidiana. Dedicou-se, em outras palavras, a pensar a anima mundi: a alma 
do mundo. Segundo Hillman, não vivemos em um mundo inanimado, mas, ao invés, em um mundo pleno de significação simbólica, "almado", em constante diálogo com os seres humanos que nele estão inseridos. Todas as coisas nos falam. O autor assim define a anima mundi:

Imaginemos a anima mundi como aquele lampejo de alma especial, aquela imagem seminal que se apresenta, em sua forma visível, por meio de cada coisa. Então, a anima mundi aponta as possibilidades animadas oferecidas em cada evento como ele é, sua apresentação sensorial como um rosto revelando sua imagem interior - em resumo, sua disponibilidade para a imaginação, sua presença como uma realidade psíquica [...] O mundo se revela em formatos, cores, atmosferas, texturas, uma exposição de formas que se apresentam. Todas as coisas exibem rostos, o mundo não é apenas uma assinatura codificada para ser decifrada em busca de significado, mas uma fisionomia para ser encarada. Como formas expressivas, as coisas falam: mostram as configurações que assumem. Elas se anunciam, atestam sua presença: "Olhem, estamos aqui" (HILLMAN, 2010, p. 89-90, grifo do autor).

Nessa perspectiva e conforme uma expressão famosa do poeta francês Paul Valéry, $o$ mais profundo é a pele. Capturamos a alma do mundo material em sua superfície - e ela, por seu turno, remete-nos às profundezas psicológicas abrigadas nas coisas. Veja-se esse exemplo:

Qualificar um prédio de "catatônico" ou "anoréxico" significa examinar o modo como ele se apresenta, seu comportamento em sua estrutura descarnada, alta, rígida, magra, sua fachada envidraçada, frieza dessexualizada, sua explosiva agressividade reprimida, seu átrio interior vazio seccionado por colunas verticais (HILLMAN, 2010, p. 92).

O prédio feio e rígido nos fala de sua feiura e rigidez, sua "alma" comunica-se com a nossa e ambas se unem: sentimo-nos negativamente impactados por essa forma arquitetônica agressiva, pouco acolhedora, marcada pela frieza de suas linhas.

A alma dos lugares e das coisas não é uma criação individual. A alma se sedimenta no tempo e resulta de diversos investimentos criativos e imaginativos de sujeitos diversos. $\mathrm{O}$ exemplo do trem e das estações de trem é bastante elucidativo a esse respeito:

Tomemos o trem: no início era considerado um terrível monstro fumegante e barulhento, completamente privado de alma. Mas através dos filmes (Mastroianni, o cinema noir, as histórias de amantes nos trens, as locomotivas nos filmes western com os internos rococó, os sequestros, os comboios dos partigiani e do holocausto...), o trem assumiu uma imagem nostálgica. E a estação ferroviária, com suas chegadas e suas partidas, se torna "superanimada", um fenômeno repleto de alma (HILLMAN, 2004, p. 96, tradução nossa).

Torna-se bastante claro pela exposição de Hillman que os investimentos imaginativos são de fundamental importância para transformar um mundo mudo em um mundo falante. E 
quem melhor que as crianças para imaginar o mundo e fazê-lo falar plenamente aos sentidos? É o que veremos logo adiante ao nos debruçarmos sobre o conto "O passeio", do escritor paulista João Anzanello Carrascoza, que narra o passeio de duas crianças pela cidade de São Paulo: ao verem o ordinário cotidiano com os olhos do extraordinário as crianças nos alertam justamente para a importância de ver as construções da cidade com a devida atenção — não simplesmente passar pelas coisas, apressadamente, mas vê-las de fato, apreciando as singularidades de suas almas. Mas por ora continuemos um pouco mais com Hillman, voltando-nos para suas reflexões mais diretamente ligadas ao fenômeno da cidade.

Em ensaio justamente intitulado "Città e anima" ("Cidade e alma"), Hillman procura reafirmar os elos que existem entre alma e cidade. $\mathrm{O}$ autor parte de uma crítica a certa visão, bastante generalizada, de que apenas o mundo natural possui alma: por conseguinte, as pessoas buscam uma vida melhor, presumivelmente mais autêntica, mediante um retorno à natureza, longe da cidade. Contrapondo-se a essa concepção, que exerce, diz, um "fascínio sentimental", Hillman afirma que também na cidade há alma. Como a alma humana, por exemplo, também a cidade possui profundidade, o seu lado obscuro, seus mistérios, que só podem ser descobertos por aqueles que ousam se aventurar em seus meandros, lugares proibidos, ruelas estreitas com curvas que não permitem uma visão total do que vem pela frente... A ideia de alma é comumente associada à memória emocional: e também na cidade os lugares tornam-se experiências emocionais, seja para um indivíduo ou para uma comunidade; justamente por isso encontramos a memória de heróis ou benfeitores da cidade na denominação de certos lugares, o que é um modo de prestar homenagem àqueles que despertaram emoções no passado e que são figuras importantes enquanto elos de identificação comuns a todos os cidadãos que fazem o hoje da cidade.

Por fim e provavelmente mais importante: quando se pensa em alma o que vêm à mente, talvez em primeiro lugar, são as relações entre os seres humanos, especialmente aquelas que se dão face a face. As almas humanas se comunicam. Nesse ponto Hillman estabelece o vínculo mais fundamental entre alma e cidade:

Como estudamos um ao outro, como nos olhamos face a face, como nos lemos - é assim que se dá o contato da alma. Uma cidade, portanto, tem necessidade de lugares para esses contatos humanos à altura do olho. De lugares de encontro. Um encontro não é apenas um encontro público, é um encontro em público [...] Passear, comer, papear, mexericar. Para a vida da cidade são enormemente importantes esses lugares onde se possa papear (1999, p. 82, tradução nossa).

O que teria levado os homens, num passado muito remoto, a se reunirem nesses conglomerados a que vieram chamar-se de cidades? Motivos políticos? Motivos econômicos 
e administrativos? Sem desconsiderar tais hipóteses, Hillman propõe uma explicação mais simples e ao mesmo tempo mais essencial:

Somente em data recente, naturalmente, pensamos que o objetivo das cidades seja econômico ou político. Desde o início o objetivo da cidade foi alguma coisa de instintivo nos seres humanos, que os levava a construí-las: a exigência de estar juntos, de imaginar, falar, fazer, trocar (Hillman, 1999, p.83).

O desejo pelas coisas construídas no meio urbano tem a ver com as possibilidades que esse meio proporciona de encontros humanos: "A cidade se funda sobre relações humanas, sobre relações das pessoas que estão juntas; e isso, no caso, aumenta as próprias coisas que são desejáveis em uma cidade" (Hillman, 1999, p. 83).

Por fim, é sempre preciso estar atento à cidade, imaginando-a repetidamente, vale dizer, criando imagens que nutrem nossa alma de estímulos e desejos de vivenciá-la. Hillman o diz exemplarmente numa frase que não por acaso escolhemos como epígrafe deste ensaio: "A cidade, a maior dentre as obras de arte humanas, pertence ao reino da imaginação" (HILLMAN, 2004, p. 96, tradução nossa). A cidade, enfim, como poiesis: projetada não somente com o espírito técnico de solucionar problemas de moradia e locomoção, mas com o desejo de criar obras de arte.

A cidade pede para ser descoberta por novas percepções, por novas formas de projeção; a cidade secreta, a cidade eterna que nasce imprevista, instantânea da imaginação e surpreende o coração. Podemos entrevê-la através de uma porta, refletida em uma poça, imagem atrasada de um portão que se fecha. A cidade pertence ao saxofone. E aos poetas imagistas. No poema In a Station of the Metro, Ezra Pound propõe "a aparição desses rostos na multidão" como "pétalas em um negro ramo úmido". Uma imaginação erótica impregna as grandes cidades (HILLMAN, 2004, p. 99).

Uma "imaginação erótica": Eros, o mais antigo dos deuses, que gera o desejo que move os seres humanos rumo ao desconhecido, ao prazer do encontro inesperado e a cada vez original.

Posto isso, vejamos o conto "O passeio", de João Carrascoza, que integra o livro Aquela água toda. $\mathrm{O}$ volume enfeixa contos do autor que exploram pequenos acontecimentos do cotidiano (aparentemente) banal, mas que, à luz do tratamento literário apurado do autor, revelam-se de grande significação para as personagens: encontros fortuitos capazes de mudar uma vida, amizades, mudanças, relações familiares, apertos financeiros, um animal doméstico que morre. A pequena experiência pode ser bem aquela que ficará gravada mais fortemente na memória afetiva. "O passeio" é exemplar nesse sentido. Tudo começa com um anúncio do pai para os filhos:

Aconteceu que o pai, à mesa de jantar, disse de repente: Sábado vamos lá. A menina, mais rápida que o irmão, perguntou, Lá onde, pai?, e ele, Não posso falar, é surpresa, e o 
garoto, Fala pai, aonde a gente vai?, e ele, já vendo a felicidade futura dos filhos, sorriu, enigmático, Sábado, à tarde!, e continuou a comer, como se nada tivesse acontecido o mundo de sempre funcionando (CARRASCOZA, 2018, p. 66, grifos do autor).

Sábio esse pai que sabe atiçar a imaginação das crianças! O fato de não revelar o lugar do passeio é justamente o estopim de uma felicidade doravante incontida: "aquele 'lá' tinha sido vento em brasa, eles ardiam de curiosidade" (CARRASCOZA, 2018, p. 66). Onde, o que seria? Procuram adivinhar: "shopping, karaokê, Playcenter?” (CARRASCOZA, 2018, p. 68). Ainda a esta altura nem as crianças nem o leitor sabem onde é o "lá" (que só será desvelado ao fim do conto, mantendo-se suspensa a definição, para deleite das crianças e também... do leitor - o conto tira muito da sua força, aliás, desse habilidoso retardamento da revelação essencial). De passagem vale notar aqui que a referência ao Playcenter indica que a ação se passa na cidade de São Paulo, pois se trata de famoso parque de diversão existente na capital paulista entre os anos de 1973 a 2012 (afora isso, a cidade permanece sempre não nomeada ao longo da narrativa, embora as indicações esparsas deixem claro que se fala aí de uma cidade grande).

Antes do passeio, há o passeio imaginado pelas crianças. Verena Kast, em livro intitulado A alma precisa de tempo, destaca o enlace entre imaginação e alegria: "A melhor alegria é a alegria antecipada. A alegria antecipada vive no futuro e, portanto, completamente da imaginação, mas ela também vive da imaginação do futuro" (KAST, 2016, p. 40). É exatamente o que vivem os irmãos: experimentam a alegria antecipada ao simultaneamente imaginarem o futuro; Carrascoza cria uma imagem literária de grande beleza para dizê-lo ao descrever as crianças na cama à hora de dormir, quando estão ainda sob a forte emoção da promessa paterna:

Não podiam se conter, os dois estavam além dessa noite. E era hora de dormir. Como manter a calma com aquela alegria, ainda sem forma, lá na frente? Sonhavam sem sono em suas camas. Reviravam-se, igualmente, nas dobras do lençol e da imaginação (KAST, 2016, p. 68).

Insistimos aqui no fenômeno da imaginação, pois ela é de fundamental importância na experiência concreta do passeio pela cidade. Como se verá, a grandeza do passeio só é concebível porque transfigurada pela imaginação infantil. A cidade vista pelos olhos das crianças é uma cidade mágica, ela surge "instantânea da imaginação e surpreende o coração", para retomar aqui as palavras de Hillman citadas mais acima. Chegado o sábado à tarde e preservado o mistério do "lá" — “o pai com o novelo da surpresa só para ele" (CARRASCOZA, 2018, p. 70) — a família toma um ônibus e inicia o passeio. As crianças estão alvoroçadas e brincam entre si:

Os dois irmãos continuavam sem saber onde era lá, mas já provavam uma alegria modesta. E trataram de engordá-la: uma freada no ônibus os atirou um sobre o outro, e eis que riram, gargalharam. A mãe de olho, Cuidado, segurem firme!, o pai feliz 
também, era isso o que desejava, os filhos daquele jeito, o bom da diversão era ela toda — o caminho (CARRASCOZA, 2018, p. 71, grifos do autor).

As crianças se divertem, riem alto no ônibus... A propósito da expressão da alegria infantil Verena Kast faz uma observação interessante:

Talvez ainda nos lembremos de como, quando crianças, expressamos nossa alegria sem vergonha em gestos e movimentos físicos, em gritos e cânticos. E de como, ao longo da vida, passamos a refletir sobre como expressar alegria para não parecermos infantis aos olhos dos outros ou para não provocar inveja (KAST, 2016, p. 47).

Conforme a argumentação de Kast, as crianças sabem ter tempo para a alegria, e isso é um exemplo que deve ser levado a sério pelos adultos, pois a alegria é uma emoção de grande importância para manter a vivacidade da alma: "Apenas quando nos alegramos verdadeiramente com algo, podemos ter a sensação de que aquilo realmente nos pertence, de que aquilo é parte da nossa vida, e contribui para nossa identidade" (KAST, 2016, p. 48). Em "O passeio" a imaginação infantil vai de mãos dadas com a felicidade: "Primeiro, da janela, viram o bairro de sempre, Olha, olha, o supermercado, a igreja, a escola: tudo há muito conhecido, embora fosse um ver novo, com o contentamento" (CARRASCOZA, 2018, p. 71, grifos do autor). A imaginação e a felicidade devolvem uma cidade renovada às crianças: eis aí "um ver novo", um recriar a cidade certamente ligado à sensação — para retomar a reflexão de Kast — de que ela nos pertence e tem a ver com a formação de nossa identidade.

Sabiamente, ainda outra vez, o pai intui a importância do caminho; não importa tão somente o lá a alcançar, o caminho faz a felicidade daquele que se desloca. E é no caminho que as crianças no ônibus veem o avião, muito mais próximo que o normal, avião que se revelará pouco adiante o prenúncio exato do destino:

Até então tinham visto os aviões pequenos, no muito alto céu, entre nuvens, sem os detalhes de agora e - descobriam, naquele momento - que eram, em verdade, sempre grandes. Tão despropositada era essa visão, que cutucaram o pai e a mãe perguntando o óbvio, se também tinham visto, como se o avião fosse um passarinho e só o olhar atento, de criança, pudesse percebê-lo na paisagem (KAST, 2016, p. 73, grifo nosso).

A passagem acima mostra muito bem como se trata de um passeio de revelação, de descobrimento das coisas urbanas, da "alma" específica que possa ter uma grande cidade em toda sua singularidade. O aprendizado se dá no aqui e agora do percurso - "descobriam, naquele momento" - descobriam, por exemplo, que o avião é diverso de como até então o concebiam. No alto do céu parece pequeno, mas agora, próximo ao ônibus, revela-se como de fato é... A aparição do avião, por fim, marca a chegada ao lugar do passeio: 
Era lá, o pleno passeio. O coração deles estremecia, com os primeiros encantos... Dali, podiam avistar a entrada principal do aeroporto, a torre de controle, um trecho da pista onde um avião taxiava lentamente, sem que soubessem se era sua partida ou chegada. Também não importava: só queriam vê-lo, com os olhos da certeza, aquele era o instante, sem o antes e o depois, o imediato real - o avião, sólido, movia-se, mais e mais, fora da neblina do sonho (KAST, 2016, p. 73, grifo nosso).

Pode parecer, em um primeiro momento, que o lugar escolhido pelo pai, enfim, é bastante comum, sem maiores ou especiais atrativos: o aeroporto da cidade... Sem dúvida não é essa a perspectiva das crianças, que ficam maravilhadas com aquilo que veem. E é lícito supor que para muitos leitores do conto - como ocorre com este que aqui escreve - o passeio narrado por Carrascoza traga à lembrança a primeira visita que fizeram a um aeroporto durante a infância e o encantamento sentido ao verem os enormes aviões pousando ou decolando... Como os trens e as estações de trem no exemplo de Hillman, também um aeroporto é um lugar "superanimado", isto é, repleto de alma, de reverberações simbólicas como lugar de encontros e reencontros, partidas, despedidas, o início de uma aventura em outro país desconhecido.

Da passagem citada acima gostaríamos de destacar ainda dois pontos inter-relacionados. O primeiro refere-se à felicidade, que é uma experiência de vinculação temporal bastante específica. Quando felizes, não pensamos nos problemas do passado e nem nos compromissos assumidos para o futuro ou nas expectativas em relação a ele. A felicidade enraíza fortemente o sujeito no presente, naquilo que ele vive no aqui e agora. É exatamente o que experimentam as personagens do conto: vivem "o instante, sem o antes e o depois, o imediato real". Os momentos de felicidade são sempre curtos, mas de grande densidade espiritual e por isso mesmo depositamse em nossa memória afetiva e retornam sempre, transfigurados, ao longo dos anos.

Vinculado à felicidade temos aí a ação de ver e rever com atenção. As vivências urbanas se fazem quase sempre em ritmo acelerado; vê-se muita coisa, mas vê-se mal, rapidamente, sem se atentar para os detalhes. De modo geral há em processo hoje uma aceleração progressiva das experiências cotidianas, que redefine em um nível difícil de precisar a própria percepção humana: os computadores, a internet, as redes sociais, especialmente, treinam nosso olhar para a fugacidade, estimulam uma espécie de técnica do olhar para apreender aquilo que passa rápido para dar lugar a outro tipo de informação em palavras ou imagens que são quase sempre apreciadas a cada vez de supetão. Televisão, computadores e outras mídias podem ser compreendidos como verdadeiras "escolas de desatenção", cuja lição estendemos a outros campos de experiência, incluindo aquele que diz respeito ao usufruto da cidade.

No caso do conto nota-se que os irmãos querem ver as coisas do aeroporto "com os olhos da certeza". Trata-se aqui de uma experiência de visão qualitativamente diversa daquela marcada pela tirania do relógio, da aceleração. Em outros termos, trata-se de ver e rever as coisas com o devido respeito - e com isso aumentar o respeito na relação estabelecida com 
as coisas. Pois não é outro o significado profundo da palavra respeito: em latim re-spectare: precisamente, olhar de novo. É o respeito infantil pelas coisas que garante aos personagens apreender o "imediato real", e a beleza e os encantos do mundo material construído. A cidade como obra de arte, como poiesis. E aqui, inevitavelmente, nos lembramos de um conhecido poema de Oswald de Andrade, "3 de maio", que diz dessa capacidade infantil de ver nas coisas aquilo que em geral passa desapercebido aos adultos e que não é senão a poesia das coisas: "Aprendi com meu filho de dez anos/ Que a poesia é a descoberta/ Das coisas que eu nunca vi" (ANDRADE, 1991, p. 99).

No conto de Carrascoza enfatiza-se essa poesia das coisas nunca vistas (ou vistas sem a devida atenção) que circula como energia anímica dos filhos para os pais. Já dentro do aeroporto a família desloca-se por entre as pessoas, e novamente vale a pena retomar aqui a reflexão de Hillman a propósito da importância dos lugares públicos nos quais as pessoas se encontram face a face, à altura do olho, e uma alma enfim se comunica com a outra: não apenas um encontro público, mas um encontro que se dá em público. E é essa situação particular que permite que algo de um ser humano — ainda que calado, embora muito melhor se papeando — se transmita a outro numa cidade.

O último parágrafo do conto nos apresenta pais e filhos enfim no mirante, ao lado de outras pessoas que também observam o movimento das aeronaves, e é esse o ponto culminante do passeio:

\begin{abstract}
Subiram, a curiosidade acelerada. Um andar mais calmo, e também eles num novo estado, acima. Ali, o mirante. Uma aglomeração de pessoas em frente à imensa janela panorâmica. Todas para ver além do vão do seu dia. Os irmãos achataram o nariz no vidro, como se quisessem transpô-lo. Latejava nos dois a felicidade, e era muita: até incômoda. Assistiam àquele trecho do mundo, inteiros, que tudo o mais era de força menor. O quadro se fazia e se refazia, móvel: dezenas de jatos estacionados com as portas abertas; ao redor, um ir e vir de tratores e ônibus, o sol atrás dos prédios, e, tocando a pista, agora pousava um avião. Olha lá! olha lá!. Chegava, enfim, a hora máxima (CARRASCOZA, 2018, p. 74, grifos do autor).
\end{abstract}

O parágrafo enfeixa com grande capacidade de síntese e beleza plástica (o mirante, as pessoas, o sol entrevisto, o avião que pousa...) aquelas que julgamos serem as duas principais linhas de força do conto: a felicidade das crianças com o passeio e a visão aguçada ou renovada sobre a cidade. A felicidade que, como já observado, vai de mãos dadas com uma capacidade de vivenciar o presente imediato, sem o antes nem o depois, o "imediato real". E a visão (cuja contraface é a fértil imaginação material das crianças) que permite novas projeções e relações afetivas com a cidade, um demorar-se amoroso em suas particularidades - uma exploração, enfim, da alma urbana. 
Carrascoza se vale de uma imagem muito apropriada para dar conta dessa visão atenta e também carregada de emoção: as pessoas estão no mirante do aeroporto para "ver além do vão do seu dia". Apropriada porque justamente enlaça o ato de ver ao ato de imaginar, sugerindo uma espécie de transcendência do visto rumo ao imaginado. Ver além do vão do dia significa, em última instância, "desanestesiar" o olhar, aguçá-lo de tal forma que o dado visto permita o voo do pensamento para além da rotina diária, contribuindo assim para uma vivificação plena da alma.

Gostaríamos de concluir este ensaio reportando-nos a outro texto sobre São Paulo, brevíssimo, e que nos parece iluminar e dialogar bem com o conto de Carrascoza. Trata-se do texto intitulado "São Paulo", que faz parte do livro de contos Breve cartografia de lugares sem nenhum interesse, do escritor mineiro Marcílio França Castro. Como indica o título da obra, boa parte das narrativas curtas tem como fulcro a apresentação de lugares que podem parecer desinteressantes a um primeiro olhar. A atenção, literariamente construída, de narradores e personagens a esses lugares pouco atrativos produz então um efeito oposto: mesmo o lugar mais trivial pode ganhar novas significações e novas relações afetivas que com ele são estabelecidas, seja um ambiente externo ou às vezes a própria casa do sujeito que por algum motivo a revê e se espanta com aquilo que está sob seus olhos todos os dias...

Leia-se o texto:

Você não entende nada de São Paulo. O que menos importa aqui, meu amigo, é esse barulho, o tumulto dos carros e do metrô, a fúria conhecida dos pedestres. O que menos importa aqui é a agitação, a insônia, a loucura. O que importa nesta cidade, meu amigo, e não pode ser gravado nem fotografado, o que você tem de se esforçar para perceber - e faça isso como quem olha nos olhos de um búfalo - é o silêncio dessas estruturas (CASTRO, 2011, p. 81).

Como ocorre no passeio narrado por Carrascoza, aqui também acontece uma espécie de reencantamento da cidade. Alguém não identificado dirige a palavra a outra pessoa, chamada de "meu amigo", uma conversa entre pares. Desde logo visões preestabelecidas são deslocadas à margem: São Paulo como a cidade do trânsito infernal, da pressa de pedestres, da insônia, da loucura, da agitação. Não se nega a existência dessas características, elas existem, mas são o "que menos importa". Podemos cogitar que o objetivo do texto é justamente colocar em crise determinados estereótipos da percepção, consolidados ao longo de muito tempo, verdadeiras lentes através das quais vemos sempre a mesma cidade.

Mas há algo mais importante, algo que não pode ser gravado ou fotografado. A alusão a meios técnicos de captação de sons ou produção de imagens é significativa. Vive-se hoje uma saturação de imagens, e é lícito supor que tal acúmulo extravagante mais esconda do que revele: quando se vê pretensamente "tudo", vê-se mal, perdem-se os detalhes e as singularidades das coisas, a alma única de que são portadoras. 
"Você tem de se esforçar para perceber". O que importa da cidade parece escapar a uma visão descuidada, veloz, que não se detenha em seus objetos. É necessário um esforço para bem notar, para bem ver. O olhar necessita de tempo, de recolhimento; o olhar, como nos ensinaram os gregos, tem a ver com a questão da verdade - saber olhar é des-velar. Desvelar São Paulo, eis o ponto crucial.

O que se propõe em seguida é que o esforço para perceber seja realizado "como quem olha nos olhos de um búfalo". Trata-se aqui de clara referência ao conto "O búfalo", que fecha o livro Laços de família, de Clarice Lispector. Nele, uma mulher em forte crise existencial passeia pelo jardim zoológico, meditando sobre sua infelicidade, e por fim desmaia ao olhar detidamente um búfalo, que lhe devolve o olhar. A referência a Lispector é muito feliz, se lembrarmos que a visão, em especial a visão profunda e atenta, de algo inesperado ou perturbador, é uma característica recorrente em vários textos da escritora. Uma mulher que vê um cego mascando chicletes, ou um rato morto sobre o calçadão de Copacabana, ou simples rosas, ou uma barata, e cada uma dessas visões detona nas personagens correspondentes uma reflexão profunda, uma revisitação, uma revisão da própria vida, das escolhas e renúncias feitas. Em resumo, em Lispector a visão é sempre aguda e atrelada a processos psicológicos profundos que supõem modificações nas percepções e conceitos preestabelecidos.

Munido dessa percepção aguda é que se pode apreender algo de diferente na cidade de São Paulo, por exemplo, o "silêncio" das estruturas urbanas. Certamente também a megalópole possui seus casulos de silêncio que só aos esforçados se dão a notar. $O$ final do texto é enigmático e abre para várias interpretações possíveis. É indubitável, todavia, que o silencio aludido se opõe às características urbanas citadas inicialmente: tumulto dos carros, agitação dos pedestres, barulho, insônia, loucura. Poderíamos dizer que tais características estão à flor da pele urbana, são facilmente apreendidas e capturadas pelo senso comum: veiculadas à exaustão pelas pessoas, acabam elas por formar a imagem mais sólida e consolidada da cidade. Daí que para apreender algo diferente e propor outra visão é preciso esforço.

Notemos, por fim, que o silêncio - de que andamos tão necessitados em nossos dias! - é um elemento que condiz perfeitamente com a imaginação. Pois o silêncio é terreno dileto da imaginação, é nele que a imaginação tende a se adensar e a se espraiar em imagens ricas de significação e afeto. Não à toa, para ficarmos com um exemplo clássico, a leitura é uma atividade que realizamos em silêncio, o que favorece enormemente o trabalho do imaginário e da produção de sentidos para os textos.

Retornamos então ao passeio de Carrascoza para concluirmos: observamos ali como a imaginação infantil pode transformar um passeio aparentemente banal, um deslocamento até o aeroporto, numa verdadeira festa dos sentidos. Revemos a cidade pelos olhos das crianças, literalmente. Uma cidade revista, ou, em outras palavras: reimaginada com uma percepção que não se descola dos afetos. Nessa perspectiva, podemos pensar o conto como uma lição de 
percepção que as crianças fornecem aos adultos: um olhar aguçado, capaz de novas projeções e imaginações ou, ainda, um olhar capaz de poesia, como está no poema de Oswald de Andrade. Já "São Paulo", de Marcílio França Castro, parece justamente reverberar tal lição ao sugerir que a metrópole pode ser apreendida, agora por um adulto, em suas manifestações menos aparentes, desde que o observador esteja disposto ao esforço de ir além do óbvio e da opinião consolidada pelo senso comum. Passeios pela cidade que a fazem falar, revigorada, aos sentidos e ao coração.

\section{Referências}

ANDRADE, Oswald de. Pau-Brasil. 5. ed. São Paulo: Globo, 1991.

CARRASCOZA, João Anzanello. O Passeio. In: . Aquela água toda. Rio de Janeiro: Alfaguara, 2018.

CASTRO, Marcílio França. São Paulo. In: . Breve cartografia de lugares sem nenhum interesse. Rio de Janeiro: 7 Letras, 2011.

HILLMAN, James. Città e anima. In: . Politica della bellezza: a cura di Francesco Donfrancesco. Traduzione: Paola Donfrancesco. Bergamo: Moretti \& Vitali, 1999. . L'Anima dei luoghi: conversazione con Carlo Truppi. Milano: Rizzoli, 2004. . Anima mundi: o retorno da alma ao mundo. In: O pensamento do coração e a alma do mundo. Tradução: Gustavo Barcellos. Campinas: Verus, 2010.

KAST, Verena. A alma precisa de tempo. Tradução: Markus A. Heidiger. Petrópolis: Vozes, 2016.

\section{Minicurrículo}

Pascoal Farinaccio é doutor em Teoria e História Literária pela Universidade Estadual de Campinas (Unicamp), com pós-doutorado pela Università di Bologna (2015). Professor de literatura brasileira na Universidade Federal Fluminense (UFF), publicou os livros Serafim Ponte Grande e as dificuldades da crítica literária (Ateliê Editorial, 2001), Oswald Glauber: arte, povo, revolução (EdUFF, 2012) e A casa, a nostalgia e o pó: a significação dos ambientes e das coisas nas imagens da literatura e do cinema: Lampedusa, Visconti e Cornélio Penna (Relicário, 2019). 